\title{
A Psicanálise no encontro com outras práticas institucionais
}

\section{Practical application of psychoanalysis in institutional practices}

\author{
Mara Caffé 1
}

Caffé M. A Psicanálise no encontro com outras práticas institucionais. Saúde, Ética \& Justiça. 2006;11(1/2):36-44.

RESUMO: Neste artigo, busca-se pensar a Psicanálise fora do contexto habitual da clínica, nas ocasiões em que é chamada a colaborar com as práticas do Direito. Constitui-se, aí, um terreno institucional híbrido, em que a função da escuta analítica se articula à função normativa jurídica. Tal situação implica a tomada do dispositivo psicanalítico em novas condições, sendo necessário redefinir os conceitos de transferência e sintoma com os quais se opera.

DESCRITORES: Psicanálise/tendências. Psicanálise/legislação \& jurisprudência.

\footnotetext{
1 Psicanalista, doutora pelo Instituto de Psicologia da USP, membro e professora no Departamento de Psicanálise do Instituto Sedes Sapientiae, São Paulo, SP

Endereço para correspondência: e-mail - maracaffe@uol.com.br
} 
desenvolver metapsicologia nestas e para estas situações requer, de modo bastante preciso, considerar nossos interlocutores, compreender criticamente seus dispositivos metodológicos próprios, compor e decompor com estas práticas a re-escrita de conceitos que nos são caros, como, por exemplo, os de transferência e sintoma. $E$ as complicações começam aqui. $O$ caso é que estas operações requerem da psicanálise tanto firmeza em relação à especificidade do seu método, quanto capacidade de se deixar modificar, alterar e mesmo distorcer. E para isto não basta boa vontade. É necessário desenvolvermos recursos conceituais que, atendendo à singularidade do nosso campo, possam permitir um grau de porosidade maior, tendo em vista a interlocução mais ampla junto de outras práticas que nos são estranhas.

Vamos pensar esta questão a partir do conceito de sintoma, peça-chave de nossa jornada. O sintoma com que trabalha o psicanalista no contexto do consultório, dos hospitais ou das escolas pode ser definido pelos mesmos elementos teóricos e metodológicos? Ou a sua compreensão requer, em cada caso, a mobilização de recursos de outros campos institucionais? Como pensar as condições de pesquisa e abordagem do sintoma nestes diversos contextos, ou seja, como pensar a transferência em modelos tão distintos da clínica convencional? Tratase, aqui, da comparação de atividades psicanalíticas bastante diferentes. Para realizá-la, seria interessante nos acercarmos dos conceitos originários de sintoma e transferência. Comecemos, então, por considerar a situação estabelecida na clínica das neuroses, conforme os parâmetros da experiência freudiana, deixando de lado as particularidades colocadas no tratamento de outras psicopatologias, como os quadros fronteiriços, as perversões e as psicoses. Serei breve e abordarei apenas um aspecto da questão, qual seja, o sintoma numa de suas expressões particulares no âmbito da análise - a neurose de transferência.

Em Recordar, repetir e elaborar, Freud (1914) ${ }^{4}$ apresenta o processo de análise da seguinte maneira: "Toda vida, o instrumento principal para reprimir a compulsão do paciente e transformá-la num motivo para recordar reside no manejo da transferência... Contanto que o paciente apresente complacência bastante para respeitar as condições necessárias da análise, alcançamos normalmente sucesso em fornecer a todos os sintomas da moléstia um novo significado transferencial, e em substituir sua neurose comum por uma 'neurose de transferência', da qual pode ser curado pelo trabalho terapêutico. A transferência cria, assim, uma região intermediária entre a doença e a vida real, através da qual a transição de uma para a outra é efetuada. A nova condição assumiu todas as características da doença, mas representa uma doença artificial, que é, em todos os pontos, acessível à nossa interpretação" (p.169-170).

De acordo com Freud ${ }^{4}$, a análise decorre de um certo manejo da transferência pelo analista, cujo resultado é a construção de um novo conjunto de sintomas referido à situação presente do atendimento. Tal manejo consiste, basicamente, na colocação da regra fundamental da associação livre ao analisando e sua contrapartida, a atenção flutuante, ao analista. Os demais procedimentos clínicos descritos por Freud justificam-se na medida em que possibilitam a vigência da regra fundamental. É o caso, por exemplo, da posição de abstinência do analista, que, na medida do possível, não deve atender as demandas inconscientes recalcadas do analisando, expressas na transferência, prestandoIhes, contudo, continência e reconhecimento através das interpretações. Segundo Freud ${ }^{4}$, a privação de certas satisfações libidinais sintomáticas é um fator importante na análise, dando ensejo a um movimento regressivo que culmina na neurose de transferência. Mas este caminho se constrói apenas na medida em que a comunicação entre os sujeitos fique remetida à regra da associação livre, que permite a produção discursiva no acento dos processos psíquicos primários, conforme os nexos dos deslocamentos e das condensações. Estas são as vias privilegiadas de acesso às representações inconscientes. Constrange-se, assim, a ação organizada dos processos psíquicos secundários, que se mostram sempre mais recobridores das problemáticas inconscientes. Ainda é preciso dizer que o analista trabalha retornando o saber produzido nestas condições ao próprio sujeito, relançando o discurso em análise, sob transferência, o que promove as condições de um saber subjetivado, implicado com as próprias questões e desejos que o movem. Tal seria o efeito da cura, conforme as afirmações de Freud.

Vemos, portanto, que a operação analítica requer a transformação necessária dos conflitos subjacentes à neurose infantil do sujeito em conflitos passíveis de serem abordados no contexto da análise. Buscar as condições de interpretabilidade do sintoma é instituir uma nova experiência sintomática nos moldes da neurose de transferência. Podemos concluir que o sintoma do qual se queixa o analisando não se oferece à interpretação analítica de modo direto. É preciso operações mediadoras que tornem possível o acesso analítico à neurose infantil do sujeito. Freud fala do espaço da análise como um espaço intermediário entre a vida e a doença. $O$ 
que se cura, portanto, é a neurose artificialmente construída no campo transferencial, a partir de procedimentos específicos que são forjados na transmissão da psicanálise, nas instituições encarregadas da formação do analista, no âmbito das análises pessoais e dos institutos de formação.

Vale dizer que, no decorrer de sua obra, principalmente a partir dos textos relativos à segunda tópica e à segunda teoria das pulsões, Freud formulou novas idéias acerca do processo analítico, considerando, por exemplo, as questões colocadas pela compulsão à repetição, abrindo o campo da análise para experiências da ordem do irrepresentável. O conceito de transferência se alarga, vista agora como repetição do recalcado e também acontecimento inusitado forjado por ambos os agentes da análise. Em seu texto Construções em análise, Freud $(1937)^{5}$ dá o testemunho das grandes mudanças que estas idéias promoveram no dispositivo da interpretação do analista.

Tais considerações estão longe de esgotar a complexidade do que se passa numa análise, porém nos oferecem um recorte mínimo para o seguimento da conversa.

Vamos deixar, por ora, os domínios de nossa área e observar outros modos de produção institucional. Veremos que operações análogas estão presentes no engenho de outras práticas sociais. Parece bastante comum a existência de dispositivos institucionais que, em certa medida, constroem a realidade que pretendem abordar. Tomarei como exemplo a prática do direito, cuja pesquisa me ocupou durante alguns anos. Depois discutiremos sobre as condições do trabalho que se pode desenvolver entre estas duas áreas, a psicanálise e o direito, o objeto do psicanalista nestas condições e as noções de sintoma e de transferência com as quais ele pode trabalhar. Espero que esta reflexão estabeleça alguns elementos para pensar a psicanálise em conjugação com outras diversas práticas sociais, como a educação, a medicina, etc. Neste sentido, pretendo esboçar idéias que, guardadas as especificidades, possam ser generalizadas para outras situações.

O dispositivo institucional do direito é a função normativa jurídica. Vamos surpreendê-la nas condições concretas do seu exercício, no campo dos processos judiciais. De modo geral, a função normativa jurídica transforma os conflitos que chegam à instância judicial em conflitos jurídicos. $O$ processo de construção do conflito jurídico coincide com o processo de elaboração da sentença judicial que lhe põe fim, a decisão do juiz. Os chamados litigantes, quando chegam ao fórum, apresentam questões que, também neste caso, não se deixam abordar diretamente pela interpretação jurídica. É necessária a mediação de procedimentos institucionais bastante específicos que confrontam o discurso conflitivo das "partes" às normas jurídicas, que são prescrições do dever-ser da conduta humana, esquemas do tipo lícito/ilícito, certo/errado, que são aplicados pelo juiz. Aqui, podemos fazer um paralelo com a situação da clínica psicanalítica: a neurose de transferência está para a cura como o conflito jurídico está para a decisão judicial. Tratase, em cada caso, de conflitos artificialmente construídos e intermediários entre os problemas inicialmente trazidos e as soluções buscadas nestas instituições.

O equivalente ao que chamamos de cura no âmbito da clínica seria, no caso do direito, a eficácia da decisão jurídica na solução de conflitos intersubjetivos. Segundo os juristas, o que garante eficácia à decisão jurídica é o fato dela proceder de uma instância de autoridade social altamente institucionalizada e, portanto, reconhecida por todos. Este reconhecimento também é garantido por forças políticas e policiais que têm um poder concreto de sanção. Deste modo, o direito é definido pelos juristas como uma instituição social coativa, sancionadora e normativa da conduta humana, tendo por finalidade decidir os conflitos sociais com o menor grau de perturbação possível. Miguel Reale Jr. (1972), jurista brasileiro, compara o direito com a moral, por exemplo, vista como conjunto de valores de uma determinada comunidade, afirmando que a moral seria também uma instância normativa da conduta humana. Porém, segundo este autor, a diferença essencial entre eles reside no fato de que o comando do direito é de natureza objetiva, ou seja, caracterizase pelo fato de ordenar e, ao mesmo tempo, garantir o poder de exigir que se cumpra.

Vamos ao traçado de alguns procedimentos da função normativa jurídica, de acordo com Tércio Sampaio Ferraz Jr. ${ }^{2,3}$, jurista que sustenta uma visão pragmática do direito. $\mathrm{Na}$ abertura de um processo judicial, as chamadas "partes" devem, antes de mais nada, constituírem seus representantes jurídicos, os advogados, que são profissionais especializados no manejo da linguagem jurídica, linguagem técnica dotada de grande formalidade e dramaticidade. Deste modo, no âmbito do processo, as partes não falam diretamente sobre seus conflitos, exceto nas audiências, ocasiões em que se apresentam pessoalmente ao juiz. Os advogados, então, no exercício de suas funções, tomam o discurso de seus clientes e elaboram estratégias de defesa e/ou acusação, o que produz um grau de modificação ao que foi trazido inicialmente. Em alguma medida, podemos pensar que o mesmo ocorre numa análise, 
em proporções e condições que variam, pois o analista toma o discurso do analisando e o conforma aos termos da teoria que dispõe para ouvi-lo.

Dando seqüência aos procedimentos jurídicos, observamos que as partes são obrigadas a se levarem em conta no plano da comunicação objetiva. Um processo judicial muitas vezes se inicia pelo fato da comunicação entre os sujeitos estar, por suposto ou de fato, interrompida. A regra que se quer garantir, então, no trânsito jurídico é a chamada regra da exigibilidade da comunicação, ainda que a interlocução entre as partes seja vista como discussão-contra. A discussão-contra se caracteriza pelo fato de que o objeto da conversa é sempre dilemático, conflitivo, posto na condição de um impasse. O direito deve garantir condições para que esta discussão-contra não se interrompa, e que transcorra mediante regras claras, num contexto de comunicação racional e objetiva. Pois bem. Para isto, é necessário que a decisão sobre o dilema das partes seja formulada por um terceiro, o juiz. Deste modo, as partes se eximem de formular a decisão sobre seus conflitos, sendo esta uma exigência mesma da prática jurídica. Desresponsabilizadas da tomada de decisão e deslocadas de falarem diretamente sobre suas questões, delegando este papel aos respectivos advogados, as partes submetem-se, assim, aos benefícios da instituição em foco.

No processo judicial, o discurso das partes deve conformar-se a um grau máximo de objetividade, o que se garante, por exemplo, na exigência de prova jurídica aos fatos que são alegados. A prova constitui um modo de produção da verdade, e se realiza conforme meios específicos e controlados. O juiz decide os meios e as condições para a obtenção de prova, bem como os prazos para isto. O que não resiste ao dever de prova é descartado do processo, de modo que nem tudo pode ser conflito no âmbito judicial. Eis um poderoso dispositivo de "varredura" ou transformação dos aspectos mais subjetivos presentes no discurso das partes.

Ainda falta dizer que o juiz assume deliberadamente, e de acordo com a demanda e o consentimento das partes, o lugar de saber e decisão sobre os conflitos em pauta, diferentemente do psicanalista, cuja posição consiste em retornar o saber ao próprio sujeito. De qualquer modo, em ambos os casos, na psicanálise e no direito, temos uma máquina discursiva imensa operando na produção de determinados conflitos como modo de resolver... conflitos!

Para conseguir seus resultados, cada prática institucional arma uma cena transferencial genérica, onde as posições do psicanalista e do juiz são estratégicas. Os casos atendidos realizam a cena transferencial genérica conforme suas singularidades, tornando cada experiência uma experiência única e, ao mesmo tempo, reconhecida como portadora do selo da referida instituição. Vamos rever alguns aspectos da posição do psicanalista e do juiz no plano da transferência genérica.

No limite do possível, o analista se abstém de colocar suas demandas e opiniões, de emitir julgamentos sobre o que traz o analisando, implicando-o na lida com seus próprios desejos e conflitos inconscientes. Na posição de uma espécie de presença vazia, o analista estabelece um vínculo curioso com o seu parceiro, pautado na crise de certos parâmetros de objetividade e racionalidade, o que potencializa a ação dos processos psíquicos primários, abrindo o campo para o reconhecimento e o trabalho com os desejos inconscientes. Para tanto, o analista se coloca na posição de retornar o saber ao próprio sujeito, o que produz as condições de um saber subjetivado, que leva em conta as condições singulares de sua origem. Uma expressão disto é a construção da temporalidade do a posteriori, que reflete as condições de um tempo fortemente marcado pelas referências subjetivas em questão. Em estudo anterior ${ }^{1}$, cheguei a dizer que a neurose de transferência é, num certo sentido, a materialização deste tempo subjetivado, trazido para um primeiro plano das relações entre os sujeitos, em lugar do tempo cronológico e racional que marca dominantemente as relações sociais corriqueiras.

$\mathrm{Na}$ cena transferencial genérica correspondente às práticas jurídicas, o juiz toma a seu cargo a responsabilidade de interpretar e julgar os conflitos trazidos pelos litigantes, assumindo o lugar de saber, ao invés de relançá-lo ao sujeito. Além disso, o juiz comparece com um código racional préestabelecido, as normas jurídicas, situando o discurso das partes conforme as referências socialmente determinadas do certo/errado, lícito/ ilícito. Deste modo, a comunicação entre as partes é pautada na crise de certos parâmetros de subjetividade, o que se vê, por exemplo, na instauração da temporalidade burocrática dos estabelecimentos de prazo, condição oposta àquela conduzida pela regra da associação livre. Esta situação visa fabricar as condições de um saber objetivado, capaz de regular as relações entre os sujeitos a partir de referências acordadas amplamente pelo conjunto social.

Uma vez esboçadas, de modo geral, algumas condições da prática psicanalítica e jurídica em seus contextos originários, pensemos, agora, o particular encontro que estabelecem no quadro de atividades conjuntas. Podemos considerar, por exemplo, as 
atividades de perícia psicológica judicial em varas criminais, de família ou de menores; os pedidos do juiz para que o psicanalista participe de audiências; a solicitação judicial para que o psicanalista acompanhe os primeiros re-encontros entre pais e filhos depois de longo tempo de interrupção dos mesmos; os trabalhos psicanalíticos voltados para a mediação de conflitos judiciais; etc.

Estas situações implicam um campo de trabalho híbrido, em que jogam diferentes dispositivos, a escuta analítica e a função normativa jurídica, colocados na condição de colaboração, mas também, é fácil prever, na condição de disputa e resistências mútuas. Afinal, muitos dos seus procedimentos são opostos, sendo bastante provável que a aliança entre elas não se deixe realizar harmonicamente. Pelo contrário, uma luta acirrada se instala quanto à posse do objeto institucional e não há como resolvê-la na ilusão de se manterem os purismos de cada área. Ora, o que se passa é que a sobreposição das duas cenas transferenciais genéricas cria, na realidade, uma terceira cena, que não se deixa mais reduzir aos elementos iniciais. Do ponto de vista do psicanalista, é necessário considerar agora as novas posições e lugares que Ihe são arranjados na transferência, para pensar que escuta analítica pode ficar recuperada ou inventada nestas condições.

Pois bem. Nesta outra cena transferencial genérica, observamos um psicanalista revestido de fortes traços superegóicos e normatizadores, que emanam da instituição dominante em que ele está, e que, portanto, não podem... e não devem ser elididos por qualquer estratégia. De todo modo, a situação discursiva não o permitiria. A providência do nosso psicanalista deveria ser muito outra: colocar estes atributos superegóicos a serviço do trabalho. $E$ isto se faz considerando o seguinte. Primeiro, o saber produzido neste contexto híbrido retorna imediatamente à cena judicial mesma, e não a um possível lugar recôndito da subjetividade dos litigantes, que estaria a salvo da experiência judicial. Nada da transferência em questão nos autoriza a interpretar determinados fenômenos como se estivéssemos no consultório. Lembro-me, aqui, de um caso de perícia psicológica judicial cuja questão era a disputa litigiosa pela guarda de uma criança. Nas entrevistas periciais, produziu-se o efeito de um forte apagamento da filha no discurso dos pais, ao passo que sobrevinham muitas representações acerca de outro processo judicial acionado por eles, que tramitava na vara criminal e versava sobre a acusação do pai de que a mãe traficava drogas. Algo se passava entre os pais no âmbito judicial que tornava muito difícil abrir espaço para a discussão sobre a guarda da filha. De qualquer modo, seria possível, a partir da perícia, concluir sobre a posição desta criança no desejo parental? Penso que, rigorosamente, esta pesquisa não é viável nas condições transferenciais de uma perícia judicial, o que não exclui o fato de que aí possa emergir uma escuta analítica. $O$ que pôde ser trabalhado no exemplo citado foi uma nova versão da cena judiciária, construída na transferência com o perito psicanalista, desobstruindo o caminho para que se instaurasse uma ação judicial com respeito à guarda da criança. Enfim, a escuta analítica no campo da perícia está confinada aos limites da cena jurídica, e mantendo-se firme neste perímetro tem boas condições de alçar vôo. O caso é que não podemos pretender a redução do conflito judicial a um conflito todo ele processável no campo da psicanálise. Cabe refrearmos as ambições psicanalíticas de colonizar as realidades conflitivas que se desenham fora do contexto originário da clínica.

O segundo ponto a considerar sobre este campo híbrido de trabalho é que a transferência constituída nestas condições é múltipla, composta de acordo com os procedimentos de várias práticas institucionais. Trabalhar nesta e com esta superposição é lidar com uma profusão de vozes dissonantes e contraditórias que atravessam o campo transferencial. Tal condição implica levarmos em conta nossos interlocutores e seus métodos de trabalho, e operar com eles, sem medo de que a psicanálise se macule... pois ela se macula! A cena transferencial genérica em nosso exemplo deve, portanto, ser construída com o jurista, o que requer, muito concretamente, fazer conversar a psicanálise e o direito, num plano que está longe de ser um plano teórico e abstrato. Já vimos que estas duas instituições, em particular, mobilizam procedimentos bastante contraditórios entre si, de modo que representam, uma para a outra, os aspectos mais recusados no âmbito de suas ações. É neste sentido que é quase um contra-senso pedir ao psicanalista que coloque os atributos sancionadores do seu novo lugar transferencial a serviço do trabalho. É pedir ao psicanalista que opere com o seu avesso, que pratique uma descentração máxima, sem deixar ainda de ser reconhecido como um psicanalista. $\mathrm{O}$ interessante é pensar que as descobertas desta viagem ao estrangeiro retornam à própria clínica, trazendo-Ihes novos parâmetros. Este é, entretanto, assunto para outra hora.

Com o objetivo de ilustrar a cena transferencial híbrida em que opera o psicanalista no contexto judicial, gostaria de mencionar outro fragmento de perícia, cujos efeitos analíticos se mostraram surpreendentes, uma vez que possibilitaram uma 
continuidade bastante incomum do trabalho. O que se desenhou na transferência com o perito foi a repetição vigorosa de uma experiência na qual os pais da criança se achavam aprisionados, a de discutirem violentamente na presença de terceiros. Durante as sessões periciais, os pais relataram cenas incontáveis de discussões mantidas na entrada do clube, da escola, diante da filha e de parentes, o que parecia justificar, em parte, a demanda por um processo judicial que se alongava por anos, sem possibilidade de acordo. Afinal, a situação litigiosa judicial traz, ela mesma, a estrutura de uma discussão assistida (nos dois sentidos da palavra). O processo tratava da regulamentação de visitas do pai à filha, estando a menor sob a guarda da mãe. Uma vez encerrada a perícia e entregue o laudo, os pais solicitaram ao juiz alguns encontros com a perita, onde pudessem comparecer juntos para refletirem sobre os dados do trabalho. O juiz aceitou o pedido, suspendendo temporariamente a realização de uma audiência já marcada, aguardando o resultado do novo trabalho.

Esta solicitação dos pais me surpreendeu, dado que, até então, ela não fora sequer aventada no âmbito de nossas entrevistas. Os pais, inclusive, a apresentaram diretamente e em primeiro lugar ao juiz. Além disso, tal pedido não figura como algo corriqueiro nos processos judiciais. Muitas vezes o perito é chamado a falar sobre o seu laudo depois de encerrado, respondendo às dúvidas ou críticas das partes, bem como do juiz, devendo fazê-lo por escrito, nos autos do processo, ou pessoalmente, em audiência. Entretanto, algo diferente se passava neste caso. Os pais procuravam prolongar as conversas comigo, agora na condição de comparecem juntos. Como se sabe, na grande maioria das vezes, os pais em litígio são recebidos separadamente para as entrevistas periciais, tendo sido este o procedimento habitual cumprido até ali.

Iniciamos, então, a segunda etapa do trabalho. Logo na primeira entrevista, os pais tiveram uma discussão ruidosa na sala de espera do meu consultório, na presença de pessoas estranhas a eles, discussão que continuaram sem interrupção na minha presença. O que me pareceu impressionante neste caso foi a tenacidade com que se repetiam situações de briga frente a terceiros, a ponto dos pais recriarem tal situação no âmbito mesmo da perícia! Porém, que esta cena se pudesse recriar no bojo das relações com a perita psicanalista já indicava um resultado analítico do trabalho, dado que pude perceber gradativamente. É preciso dizer que condições especiais cercaram o andamento deste processo; os pais mostravam, apesar dos infindáveis ataques mútuos, bons recursos psíquicos de elaboração da problemática que foi se constituindo em presença da perita psicanalista; além disso, a condução do processo pelo juiz se deu de modo muito favorável, conforme pude constatar pelo relato dos pais acerca das suas atuações (do juiz) nas audiências. A sensibilidade com que o juiz parecia alternar posições mais normativas e mais reservadas em relação ao movimento dos pais chamou minha atenção. Enfim, nos quatro encontros que tive com os pais juntos, pudemos trabalhar o reconhecimento da série de repetições que não cessavam, na qual discutiam diante de terceiros, sendo esta a estrutura mesma das relações mantidas no âmbito do processo judicial. Os pais estabeleceram elementos para a realização de um acordo quanto à questão das visitas à filha, encerrando o processo judicial sem que o juiz precisasse ditar, ele, a sentença do acordo.

Aqui é necessário esclarecer em quê a atuação do perito-psicanalista diferiu da atuação mais típica do psicanalista na clínica. No caso citado, as questões que mantinham os pais nesta série de repetições não puderam se esclarecer no âmbito do trabalho pericial, pois não era esta a direção do trabalho, direção impossível no plano da transferência híbrida em que nos encontrávamos, associados aos procedimentos da prática jurídica. Se tal pesquisa fosse empreendida nos moldes do que observamos na clínica convencional, incorreríamos num agravamento dos conflitos encenados judicialmente e, a rigor, não obteríamos os resultados buscados. Muitas vezes ouvimos falar da atuação desastrosa de certos advogados que acirram a briga judicial em função de suas estratégias de trabalho. Pois bem. Ocorre que, muitas vezes, e movidos pelas melhores intenções, os psicólogos ou psicanalistas que trabalham na esfera judicial produzem o mesmo resultado, quando pretendem instaurar a cena clássica do consultório onde, de fato, ela não cabe. É neste sentido que mencionarei, a seguir, o risco de perpetrarmos em maior grau uma violência que é inerente à prática clínica, incluindo aqui a prática clínica no âmbito judicial. Procurar as possibilidades e limites da escuta analítica no encontro com a função normativa jurídica significa, portanto, re-desenhar a transferência e a construção sintomática com a qual vamos lidar.

É no âmbito da cena judicial que o peritopsicanalista trabalha, ainda que a sua escuta seja operada, em parte, por referentes alheios à prática discursiva jurídica. No caso em questão, a cena judicial reeditada com a perita-psicanalista, cuja recepção é distinta daquela oferecida pelos operadores do direito, criou a possibilidade do encerramento do processo, ou seja, a possibilidade dos pais realizarem eles próprios o acordo judicial, 
dispensando, neste ponto, o arbítrio do juiz, o terceiro da cena jurídica. $E$ tal foi possível também em razão da conduta bastante adequada do juiz, que "pôde" se retirar da cena quando isto se fazia sustentável, no interior mesmo do processo. Podemos ver, com este exemplo, que a atuação do juiz também se altera em presença deste parceiro que é o psicanalista. Também o juiz se achava numa rede transferencial híbrida em que a função normativa se deixava marcar por matizes diferentes daqueles da situação jurídica originária. Brincando um pouco com as palavras, podemos dizer que, neste caso, os pais compareceram juntos no lugar em que o psicanalista e o juiz trabalharam juntos, lugar simbólico construído no encontro efetivo de dois dispositivos institucionais distintos.

Com estes fragmentos de perícia, busquei ilustrar o que chamo de construção de uma nova cena transferencial genérica em que se movem o psicanalista e o jurista, embora no curto espaço deste artigo não tenha sido possível adentrar as vicissitudes da escuta analítica aí instituída. Para tanto, remeto o leitor ao livro em que detalho o assunto'.

Seguindo com as considerações sobre este novo campo de trabalho, levantarei um terceiro ponto, que decorre, na realidade, do que já foi dito: as atividades psicanalíticas híbridas demandam um forte refrear da conduta interpretativa a que estamos por que não dizer - constrangidos na clínica, mesmo quando não formulamos verbalmente nossas interpretações aos analisandos. Ocorre que a própria regra da associação livre posta a operar em boas condições simbólicas (o nosso referencial aqui é sempre a clínica das neuroses, pelo menos em um de seus aspectos...) produz sentidos que remetem a outros sentidos, qual um processo onírico que decanta num sonho, por exemplo, cujo breve enunciado guarda uma infinidade de pensamentos e relações. Pois bem. A posição transferencial do psicanalista situado no âmbito judicial, na vigência da função normativa jurídica, implica um modo de pensar bem diferente, que não depende inteiramente da escolha pessoal ou do estilo de cada psicanalista, mas emana da nova estrutura institucional a que ele está filiado. Considerar de fato o nosso interlocutor do direito, e não apenas como pró-forma, significa, num sentido muito profundo e até arcaico, pensar como ele... Poderemos nos acercar disto, sem termos a sensação eminente de que produzimos um atestado de óbito à escuta analítica? Poderemos tolerar o informe ou o disforme no coração do dispositivo que nos confere identidade? E a partir daí, qual seria o sintoma artificial constituído nestas cenas transferenciais híbridas? Como pensar o sintoma psicanalítico no fora da psicanálise?
Estas questões saem do registro da impossibilidade se considerarmos que o sintoma com que trabalhamos, em qualquer situação, na clínica ou fora dela, não é uma construção dada, que está lá antes do psicanalista chegar. É sempre a transferência, armada nas condições discursivas em questão, e seu manejo que dão as coordenadas da construção sintomática. Em minha concepção, o que define a psicanálise é a capacidade plástica de intervir na construção de sintomas que possam render sentido subjetivado. $E$ isto se consegue tanto melhor, nos campos institucionais híbridos, quanto mais dentro dos novos limites transferenciais se puder trabalhar! Fora desta condição, não apenas diminuímos o alcance de nossa compreensão, o campo de analisabilidade, como determinamos, em maior grau, uma violência que, afinal, é inerente a qualquer prática institucional. Vimos quantas coerções se aplicam aos discursos conflitivos dos sujeitos para que constituam "neuroses de transferência" ou "conflitos jurídicos"; tudo isto se produz com violência e no exercício do poder instituído de cada prática social. Assim, a violência é produtiva e constitutiva dos processos institucionais, porém é necessário que a processemos dentro de certos limites. Os psicanalistas, em seu conjunto, precisam inventar dispositivos que garantam uma vigilância constante com respeito à violência inerente de suas práticas.

No âmbito desta reflexão, um recurso seria levar sempre em conta o contexto institucional da transferência em que se trabalha. Mas o que isto quer dizer propriamente? Isto quer dizer: compor uma noção de transferência considerando os efeitos do encontro da escuta analítica com os outros dispositivos teórico-metodológicos em pauta. A construção deste campo demanda uma concepção de transferência e de sintoma que não estão dadas à priori. É necessário defini-las na conversa com o campo institucional com o qual a psicanálise se alia, o que requer, podemos dizer, um "anel de schazam", capaz de mágicas apenas quando se reúnem as suas metades. Enfim, esta construção não se resolve de modo individual, deliberado, toda ela no campo da racionalidade. É necessariamente uma construção coletiva, plural, descentrada da exclusividade da lente do psicanalista. Deixar-se analisar no próprio dispositivo da escuta, eis a posição inevitável que isto requer. Deixar o dispositivo da escuta analítica se vazar de outros dispositivos... Deixar-se, enfim, revolucionar.

Gostaria de finalizar com esta idéia, estendendo-a um pouco mais. O desencastelamento da clínica convencional exige que a psicanálise se deixe penetrar por outras práticas, desfigurar-se, para então re-fundar o que lhe é essencial. A psicanálise 
precisa, literalmente, superar seus limites, transgredilos. De tal modo que, fora da sua "casa-clínica", o psicanalista deve ser um sujeito capaz de revolta. Tomo a expressão de Julia Kristeva ${ }^{6}$, em seu livro Sentido e contra-senso da revolta. Vale a pena conferir. Permitam-me alguns parágrafos mais.

Kristeva ${ }^{6}$ descreve a realidade ocidental moderna como uma ordem normalizadora e ao mesmo tempo falsificável, ou pervertível, dentro da qual é cada vez mais difícil a experiência importante e criativa da revolta. O que se tem ameaçado é a cultura-revolta, e a autora nos chama a pensar, como sujeitos coletivos, as respostas que podemos dar a isto, ou que a psicanálise pode dar a isso. Afinal, a cultura não é um dado, tem que ser re-fundada a cada vez, a cada geração. Pois bem, a autora sublinha que no centro da fundação da cultura há um ato de revolta, conforme postula Freud no texto Totem e tabu, de 1912.

No mito que remonta à horda primitiva humana, a rebelião dos filhos contra o pai autoritário, admirado e temido, teria culminado no seu assassinato. Os irmãos, num êxtase de alegria, organizaram um ritual canibalesco e consumiram seu corpo. Neste ato, identificaram-se com o pai adorado, incorporando suas qualidades e estabelecendo, ao mesmo tempo, um sentimento de culpa pelo assassinato e o concomitante arrependimento que sela o pacto social daí por diante. E... coisa curiosa, os rituais religiosos totêmicos teriam a função de lembrar o triunfo conseguido sobre o pai, ao mesmo tempo em que renovam a culpabilidade e o laço social. Kristeva ${ }^{6}$ enfatiza que o lucro da rebelião é a apropriação dos atributos do pai. Isto justificaria o que Freud denomina como a necessidade de "mimar" a revolta. Alguns procedimentos sociais, em especial os religiosos, teriam o sentido "não de reproduzi-la tal qual, mas de representá-la em forma de uma comemoração festiva ou sacrificial..." (p. 32).

Kristeva ${ }^{6}$ conclui: Freud é "... o primeiro a sublinhar esse 'lucro da rebelião' e a nos convidar a pensar nas situações em que ele 'ameaça desaparecer' - já que é então, e somente então, que a obediência culpada cede diante da necessidade de renovar a rebelião... Quando não temos mais prazer nos laços, recomeçamos a revolta..." (p. 33). Segundo a autora, a inserção do sujeito no socius é ameaçada quando ele não pode mais retirar dali a apropriação das qualidades do pai, ou seja, identificar-se com os seus atributos, com o seu poder, sentir-se incluído na ordem social. O desemprego, a exploração no trabalho, a injustiça social, enfim, as sucessivas frustrações acumuladas durante a vida são fatores de enfraquecimento do pacto social, e estariam especialmente intensificados em nossa sociedade atual, pois o que nela se põe em cheque é justamente a capacidade coletiva da revolta. Numa expressão de Kristeva ${ }^{6}$, a situação dramática do sujeito ocidental contemporâneo é a de que ele não se sente nem culpado, nem responsável, mas sim incapaz de revolta (p. 35).

Prosseguindo, Kristeva ${ }^{6}$ vai tomar o termo revolta também no sentido de "retorno... acesso ao arcaico, a uma temporalidade fora-do-tempo..." (p. 36). Este retorno (re-volta) estaria brilhantemente figurado no romance de Proust, Em busca do tempo perdido. Pois bem, ambas as acepções do termo revolta - rebelião e retorno - poderiam ser encontradas no ato analítico, pois ele coloca em cena a experiência da revolta articulada na trama edípica e o retorno ao arcaico, às figuras do infantil.

Este passeio por Kristeva ${ }^{6}$ nos rende uma idéia interessante, a de que a castração, enquanto operação simbólica, possui o aspecto da interdição e também o aspecto da rebelião, ainda que não se trate aqui, diretamente, da rebelião primária que perpetrou o assassinato do pai primitivo. Esta seria da ordem de uma fantasia fundamental, de uma fantasia primária a ser recalcada na instituição do psiquismo. A rebelião em jogo na operação da castração seria uma rebelião secundária, tão importante para a cultura humana quanto a experiência reguladora da interdição. O que teríamos sob ameaça numa sociedade falsificável e normalizadora é justamente este aspecto da castração simbólica que é a capacidade de rebelião garantida.

Em outro livro denominado As novas doenças da alma, Kristeva ${ }^{7}$ apresenta um trabalho original com o conceito de castração que segue o mesmo princípio. Diz a autora: "Contudo, se insistimos demasiadamente apenas na negação e na rejeição que subtendem a castração simbólica, corremos o alto risco de enraizá-la apenas no luto, prometendo aos analistas e analisandos uma existência estóica... É de se perguntar se a castração simbólica, tributária da negação e da rejeição, cheia de separação e frustração, carregada de perdas oral, anal e peniana, não deve seu impacto benevolente e brutal ao fato de ser, para além da negação, uma questão" (p. 98). Assim, a castração seria possibilidade de operar sucessivas questões a partir da realidade traumática do sexual. A castração simbólica é o que torna possível fazer questão.

Praticar psicanálise junto de outras instituições, colocar a escuta analítica no encontro com outros dispositivos metodológicos implica criar um campo de diferenças. Ocorre que não há, de início, diferença alguma entre psicanálise e direito. A diferença é ponto de chegada, é uma relação a ser forjada por cada instituição num ato de rebelião e retorno ao que está na origem. 
Caffé M. A Psicanálise no encontro com outras práticas institucionais.

Caffé M. Practical application of psychoanalysis in institutional practices. Saúde, Ética \& Justiça. 2006;11(1/2):36-44.

ABSTRACT: This article aims to explore psychoanalysis outside the usual context of the clinic, focusing on the occasions it is called upon to collaborate with Family Law practice. As such, Law and Psychoanalysis constitute a hybrid institutional realm where the agency of analytical listening is articulated with the agency legal precept. Under this circumstances, the practice psychoanalysis is taken into new conditions and demands a redefinition of concepts such as transference and symptoms from their traditional use.

KEY WORDS: Psychoanalysis/trends. Psychoanalysis/legislation \& jurisprudence.

\section{REFERÊNCIAS}

1. Caffé M. Psicanálise e direito - a escuta analítica e a função normativa jurídica. São Paulo: Quartier Latin; 2003.

2. Ferraz Jr TS. Direito, retórica e comunicação. São Paulo: Saraiva; 1973.

3. Ferraz Jr TS. Introdução ao estudo do direito: técnica, decisão, dominação. São Paulo: Atlas; 1994.

4. Freud S (1914). Recordar, repetir e elaborar. In: Obras completas de Sigmund Freud: edição standard brasileira. Rio de Janeiro: Imago; 1996. v.12.
5. Freud S (1937). Construções em análise. In: Obras completas de Sigmund Freud: edição standard brasileira. Rio de Janeiro: Imago; 1996. v.23.

6. Kristeva J. Sentido e contra-senso da revolta: poderes e limites da psicanálise I. Rio de Janeiro: Ed. Rocco; 2000.

7. Kristeva J. As novas doenças da alma. Rio de Janeiro: Ed. Rocco; 2002.

8. Reale M. Filosofia do direito. São Paulo: Saraiva; 1972. 